\title{
Follicular stage-dependent regulation of apoptosis and steroidogenesis by prohibitin in rat granulosa cells
}

Qi Wang ${ }^{1,2}$, Arthur Leader ${ }^{2,3,4}$ and Benjamin K Tsang ${ }^{1,2,3,5^{*}}$

\begin{abstract}
Background: Follicular growth and atresia are tightly regulated processes, which involve the participation of endocrine, autocrine and paracrine factors at the cellular level. Prohibitin (PHB) is a multifunctional intracellular protein playing an important role in the regulation of proliferation, apoptosis and differentiation. Here we examined the expression of PHB and its regulation by FSH in vitro and studied the role of PHB in the regulation of apoptosis and steroidogenesis in response to the apoptosis inducer staurosporine (STS) and to FSH, respectively.

Methods: Undifferentiated and differentiated granulosa cells were collected from diethylstilbestrol (DES)- and equine chronic gonadotropin (eCG)-primed immature rats, respectively and then cultured with various treatments (FSH, adenovirus infection, STS) according to experimental design. The apoptosis rate, the production of estradiol and progesterone, and the expression of distinct proteins (PHB, caspase-3, phospho- and total Akt) were assessed.

Results: PHB is anti-apoptotic and its action is dependent on the differentiated state of the granulosa cells. Data from gain- and loss-of-function experiments demonstrate that PHB inhibited STS-induced caspase-3 cleavage and apoptosis in undifferentiated granulosa cells, but was ineffective in differentiated cells. In contrast, PHB suppresses FSH-induced steroidogenesis and this response is evident irrespective of the differentiated state of granulosa cells.

Conclusion: These findings suggest that PHB regulates granulosa cell apoptosis and steroidogenesis in a follicular stagedependent manner and that the dysregulation of PHB expression and action may be relevant to ovarian dysfunction.
\end{abstract}

Keywords: Prohibitin, Apoptosis, Steroidogenesis

\section{Background}

The destiny of the growing follicles (ovulation or atresia) is dependent on the fate of the cells within them (proliferation, differentiation or apoptosis) and is tightly regulated by endocrine, autocrine and paracrine factors [1]. During follicular development, a large number of follicles undergo atresia, a process tightly controlled by the cross-talk of cell death and survival signals [1,2]. The dominant follicles continue to develop to preovulatory stages, producing appreciable amounts of steroid hormones which are critical for the reproductive cycle and successful ovulation $[3,4]$.

\footnotetext{
*Correspondence: btsang@ohri.ca

'Department of Cellular \& Molecular Medicine, University of Ottawa, Ottawa, Ontario, K1H 8L6, Canada

${ }^{2}$ Chronic Disease Program, Ottawa Hospital Research Institute, The Ottawa Hospital-General Campus, Mail Box \#511501 Smyth Road, Ottawa, Ontario K1H 8L6, Canada

Full list of author information is available at the end of the article
}

Prohibitin (PHB) is a multifunctional protein highly conserved in various species, with identical amino acid sequences in mouse and rat and only one residue differing from that in human [5]. It is present in multiple cellular compartments, including nucleus, mitochondria, plasma membrane and lipid droplets, as well as in the circulation [6-10]. The subcellular localization of PHB may contribute to its diverse functions in the regulation of proliferation, apoptosis, senescence and differentiation [11-14]. For example, mitochondrial PHB facilitates the maintenance of mitochondrial morphology and stabilizes newly synthesized mitochondrial enzymes $[15,16]$. Nuclear PHB has been implicated in the regulation of gene expression by interacting with various transcriptional factors, such as E2F, p53 and estrogen receptor $\alpha(E R \alpha)[7,17,18]$.

PHB is widely expressed in the ovary and is anti-apoptotic during staurosporine (STS)- and ceramide-induced apoptosis

\section{Biomed Central}


in undifferentiated granulosa cells [19-21]. However, it is unknown whether PHB performs similar roles during follicular development. Although recent data indicated that silencing of $\mathrm{PHB}$ induced granulosa cell shape changes [22] and PHB suppressed steroidogenesis in undifferentiated granulosa cells [23], our knowledge on the role and contribution of $\mathrm{PHB}$ to granulosa cell differentiation is incomplete.

In this study, we first examined the expression of $\mathrm{PHB}$ and their regulation by FSH in vitro. Using differentiated and undifferentiated granulosa cells from distinct stages of follicular development, we compared its responsiveness to the apoptosis inducer STS and to FSH, a differentiation inducer, and also examined the role of PHB by gain- and loss-of function experiments. We also studied if the roles of $\mathrm{PHB}$ in the regulation of apoptosis and steroidogenesis are follicular stage-dependent.

\section{Materials and methods}

\section{Antibodies and reagents}

Cell culture media (M199), fetal bovine serum (FBS), penicillin and streptomycin, L-glutamine, sodium pyruvate and trypsin were purchased from Invitrogen (Burlington, Canada). HEPES, Hoechst 33258, equine chronic gonadotropin (eCG), and diethylstilbestrol (DES) were purchased from Sigma (St. Louis, MO). Recombinant human FSH was purchased from National Hormone and Peptide Program (Harbor-UCLA Medical Center, Torrance, CA). Anti-caspase-3 antibody (recognizing both intact and active caspase-3), anti-phospho-Akt (S473) and anti-Akt antibodies were purchased from Cell signaling (Danvers, MA), anti-PHB and anti- $\beta$-Actin antibodies were from Abcam (Cambridge, MA). Horseradish peroxidaseconjugated secondary antibodies and reagents for SDSPAGE were supplied by Bio-Rad (Mississauga, Canada). Enhanced chemiluminescent (ECL) reagent was from Thermo Fisher Scientific (Rockford, IL). Adenoviral-PHB, shPHB and their control particles were obtained from Dr. Winston Thompson (Morehouse School of Medicine, Atlanta). QIAShredder and RNeasy mini kit were purchased from QIAGEN (Mississauga, Canada). Random decamer primers were from Ambion (Austin, TX). Ribonuclease inhibitor and dNTP were from Fermentas (Burlington, Canada). Moloney murine leukemia virus reverse transcriptase was from Promega (Madison, WI). PCR primers were from Invitrogen. All chemical inhibitors were purchased from Calbiochem (Gibbstown, NJ). All other chemicals were of the highest analytical grade available from Sigma.

\section{Animal preparation}

Twenty one days old Sprague-Dawley rats (Charles River, Montreal, Canada) were maintained on 12-h light, 12-h dark cycles and given food and water ad libitum.
All procedures were carried out in accordance with the Guidelines for the Care and Use of Laboratory Animals, Canadian Council on Animal Care, and were approved by the University of Ottawa and the Ottawa Hospital Research Institute Animal Care Committee.

\section{Primary culture of rat granulosa cells and adenoviral infection}

Granulosa cells from eCG-primed immature rats (10 IU, $48 \mathrm{~h}$, s.c.; considered as differentiated granulosa cells) and DES-injected control rats $(1 \mathrm{mg} /$ day for 3 consecutive days, s.c.; considered as undifferentiated granulosa cells) were pre-incubated with $6 \mathrm{mM}$ EGTA and $0.5 \mathrm{M}$ sucrose [24] and were released by follicular puncture with a 26.5gauge needle, washed and centrifuged $(900 \times \mathrm{g}, 5 \mathrm{~min})$. Cell clumps and oocytes were removed by filtering the cell suspensions through a $40-\mu \mathrm{m}$ nylon cell strainer (BD Biosciences). The viability of granulosa cells was determined by trypan blue exclusion. Granulosa cells $\left(0.9 \times 10^{6}\right.$ per well in 6-well plate) were plated overnight in M199 with $10 \%$ FBS under a humidified atmosphere of $95 \%$ air and $5 \% \mathrm{CO}_{2}$. After culture overnight in serum-free medium, granulosa cells were treated with FSH $(0-200 \mathrm{ng} / \mathrm{ml})$ or STS $(1 \mu \mathrm{M})$ for a designated duration.

For adenoviral infection, granulosa cells were cultured in serum-free M199 medium containing adenoviral particles for $24 \mathrm{~h}$ followed by medium change. Multiplicity of infection (MOI) and duration of infection are detailed in the figures. Equal amounts of adenovirus in each experimental group were achieved by adjusting with an appropriate amount of adenoviral-LacZ (negative control for adenoviral-PHB) or adenoviral-shNeg (negative control for $\operatorname{sh} P H B)$.

\section{RT-PCR}

Total RNA of granulosa cells was extracted according to the manufacturer's instruction, using the QIAGEN RNeasy Mini kit. Two hundred ng total RNA were used to reverse transcribe cDNAs and the mRNA abundance of target genes was analyzed by PCR. The PHB primers used for amplification were a $5^{\prime}$ forward primer $\left(5^{\prime}\right.$ TGGCAGCCTGAGTAGACCTT-3') and a $3^{\prime}$ reverse primer $\left(5^{\prime}\right.$-TCACGGTTAAGAGGGAATGG-3'). The p450scc primers were a $5^{\prime}$ forward primer $\left(5^{\prime}\right.$-ACCCTGAGTCCCA GCGGTTC-3') and a $3^{\prime}$ reverse primer $\left(5^{\prime}\right.$-CACCCCTCCTGCCAGCATCT- $\left.3^{\prime}\right)$. The aromatase primers were a $5^{\prime}$ forward primer (5'-TGGTCCCG-GAAACTGTGCCT$\left.3^{\prime}\right)$ and a $3^{\prime}$ reverse primer $\left(5^{\prime}\right.$-CCACGCTTGCTGCCG AATCT-3'). The actin primer were (5'-CGTCCACCCGCG AGTACAAC-3') and a $3^{\prime}$ reverse primer $\left(5^{\prime}-\right.$ GCCTCTCTTGCTCTGGGCCT-3'). The thermal cycling conditions were comprised of an initial denaturation step at $95 \mathrm{C}$ for $10 \mathrm{~min}$ followed by 30 cycles amplification for $\mathrm{PHB}$, p450scc and aromatase (20 cycles for actin) at $95 \mathrm{C}$ for 
$30 \mathrm{sec}, 55 \mathrm{C}$ for $30 \mathrm{sec}$, and $72 \mathrm{C}$ for $30 \mathrm{sec}$. The PCR products were subjected to $2 \%$ ethidium bromide-containing agarose gel and visualized under UV light.

\section{Protein extraction and western blot}

At the end of the culture period, floating cells and attached cells (recovered by $0.05 \%$ trypsin treatment) were pooled and centrifuged $(1000 \times \mathrm{g}, 10 \mathrm{~min})$. For protein extraction, cell pellets were resuspended in a lysis buffer (PBS, $\mathrm{pH} 7.4$ ) containing $\mathrm{NaCl}(150 \mathrm{mM})$, SDS $(0.1 \%)$, sodium deoxycholate $(0.5 \%)$, Nonidet P-40 (1\%), and the protease inhibitor cocktail (Sigma) and kept on ice for $30 \mathrm{~min}$. Cell lysates were sonicated and centrifuged $(12,000 \times \mathrm{g}, 5 \mathrm{~min}$, $4^{\circ} \mathrm{C}$ ) to remove insoluble material. Supernatant was recovered and stored at $-20^{\circ} \mathrm{C}$ until further processing. Protein concentrations in each sample were determined by the Bradford assay (Bio-Rad Laboratories). Twenty $\mu \mathrm{g}$ of protein of cell lysates were subjected to SDS-PAGE with $4.5 \%$ stacking and $15 \%$ separating gels. Proteins were electrophoretically transferred onto nitrocellular membrane (NC, Bio-Rad), blocked at room temperature with 5\% skim milk in TBST $[0.05 \%$ Tween-20 in Tris $(10 \mathrm{mM})$ and $\mathrm{NaCl}$ $(0.15 \mathrm{M}), \mathrm{pH} 7.4$ (TBS)] for $1 \mathrm{~h}$ and then incubated overnight at $4^{\circ} \mathrm{C}$ with diluted primary antibodies (1:1000) in TBST with constant agitation. The membranes were then treated with a secondary antibody (1:2000 to 1:10,000 based on different primary antibody). After washing three times with TBST, immunoreactive bands were visualized with ECL according to the manufacturer's instruction. Intensity of bands of the exposed X-ray film was determined by densitometrically scanned, quantified, using AlphaEaseFC (Alpha Innotech, CA) and normalized with $\beta$-Actin.

\section{Assessment of apoptosis}

Apoptotic cells were identified morphologically by Hoechst-33258 (bisBenzimide, Sigma) staining as previously reported [25]. At the end of the culture period, suspended cells were collected by centrifugation and attached cells were trypsinized. The two cell fractions were then pooled, pelleted, and suspended in $10 \%$ phosphate-buffered formalin containing Hoechst 33258 $(6.25 \mathrm{\mu g} / \mathrm{ml}$; room temperature, $2 \mathrm{~h})$, Cells were then spotted on slides and assessed for typical apoptotic nuclear morphology. To quantify the number of apoptotic cells, healthy and apoptotic cells were counted (counter was "blinded to sample identity") and the apoptotic cells were expressed as a percentage of total cells. A minimum of 400 cells were counted in each treatment group.

\section{Steroids secretion analysis}

Spent medium from granulosa cell cultures were collected, centrifuged $(900 \times \mathrm{g}, 5 \mathrm{~min})$ and kept in $-80^{\circ} \mathrm{C}$ for hormone analysis. $17 \beta$-estradiol and progesterone concentrations in spent medium were measured using enzyme immunoassay kit (EIA; Enzo Life Sciences, Farmingdale, $\mathrm{NY}$ ) according to the manufacturer's instruction. The detection limitation of estradiol was $28 \mathrm{pg} / \mathrm{ml}$, and the intra- and inter-assay coefficients of variation were 8 and $6 \%$, respectively. The detection limitation of progesterone was $8.5 \mathrm{pg} / \mathrm{ml}$, and the intra- and inter-assay coefficients of variation were 7 and 6\%, respectively.

\section{Statistical analysis}

All data were analyzed using GraphPad Prism 5.0 statistical software (San Diego, CA). Results are expressed as mean \pm SEM of at least three independent experiments as detailed in the figures. One-way and two-way ANOVA were used to assess the effects and interactions of one or two variables and multiple comparisons were achieved by a Bonferroni post hoc test. Significant difference was defined at $\mathrm{p}<0.05\left({ }^{*}\right.$, or \#).

\section{Results}

\section{PHB is differentially expressed in granulosa cells from different follicular stages}

To examine whether PHB is expressed in vivo in a follicular stage-dependent manner, differentiated and undifferentiated granulosa cells were collected and the gene expression of PHB was analyzed by traditional PCR. As shown in Figure 1A, differentiated granulosa cells exhibited increased expression of p450scc and aromatase, steroidogenic enzymes known to be associated with granulosa cell differentiation. The $P H B$ expression in differentiated granulosa cells was lower than that in undifferentiated granulosa cells.

\section{FSH upregulates PHB content in differentiated but not undifferentiated granulosa cells}

To explore whether FSH regulates $\mathrm{PHB}$ expression in vitro, undifferentiated and differentiated granulosa cells were cultured with FSH $(100 \mathrm{ng} / \mathrm{ml})$ for designated time $(0-24 \mathrm{~h})$ and the contents of PHB in two types of cells were examined. As shown in Figure 1B, FSH had no effect on $\mathrm{PHB}$ content in undifferentiated granulosa cells $(\mathrm{p}>$ 0.05). In the contrast, FSH up-regulated PHB expression in differentiated granulosa cells $(\mathrm{p}<0.001)$. While there was an apparent gradual increase in PHB content with the duration of culture in the presence of FSH, significant upregulation was not evident until $24 \mathrm{~h}$. Both undifferentiated $(\mathrm{p}<0.0001)$ and differentiated $(\mathrm{p}<0.001)$ granulosa cells exhibited a rapid increase in phosphorylated Akt content; however, Akt activation in the former was stronger (6-fold vs. 2-fold change at $0.25 \mathrm{~h}$ ) and sustained longer (over basal level at 4-8h) compared with that in the latter.

We then examined whether FSH regulates PHB contents in differentiated granulosa cells in a concentration-dependent manner. Undifferentiated and differentiated granulosa cells were cultured with different FSH concentration (0-200 ng/ml) 


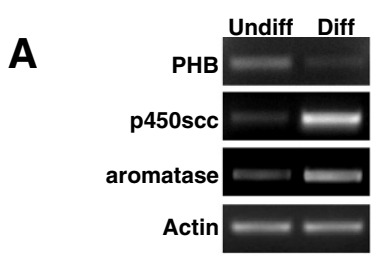

B Undifferentiated GCs

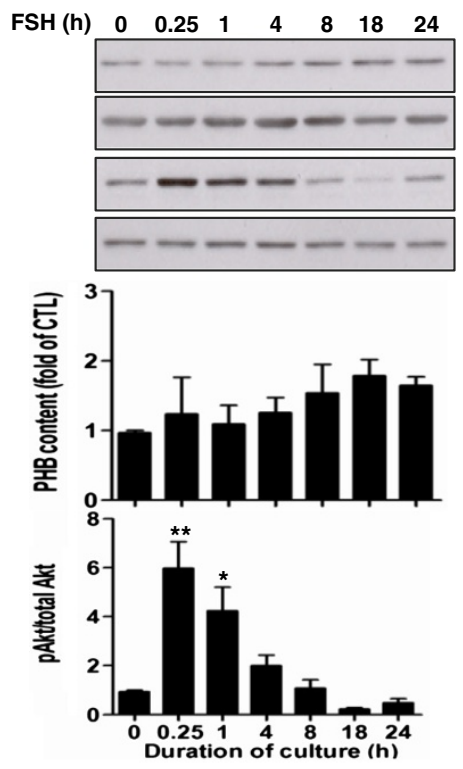

C Undifferentiated GCs

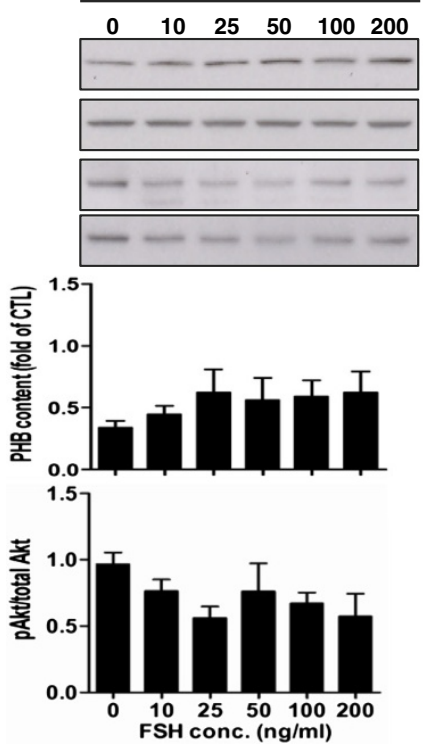

\section{Differentiated GCs}
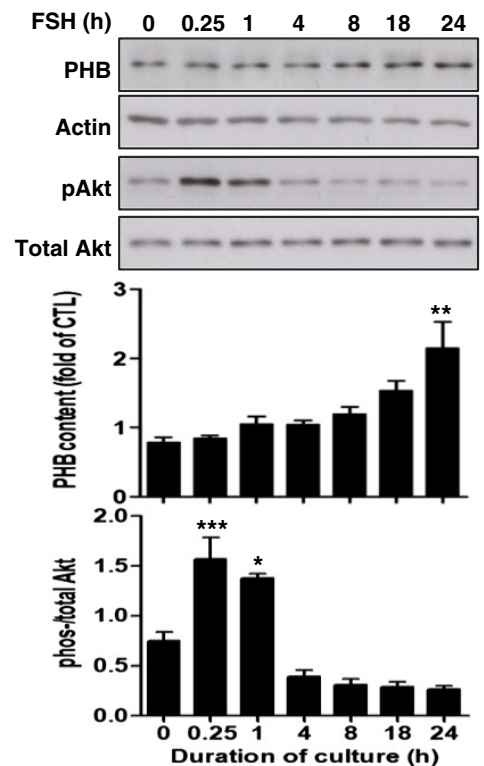

Differentiated GCs
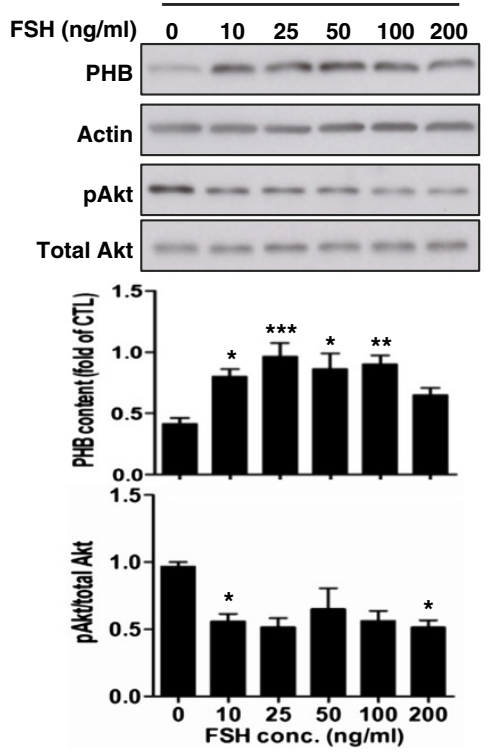

Figure 1 The regulation of PHB by gonadotropin. (A) Total RNAs of undifferentiated and differentiated granulosa cells were extracted and mRNA abundance of PHB was analyzed by PCR. p450scc and aromatase mRNA levels were assessed as differentiated marker and Actin was used as loading control. (B) Undifferentiated and differentiated granulosa cells were cultured with FSH (100 ng/ml) for designated time period and the contents of PHB, pAkt and total Akt were examined by Western blot. (C) Undifferentiated and differentiated granulosa cells were cultured with FSH $(0-200 \mathrm{ng} / \mathrm{ml})$ for $24 \mathrm{~h}$. PHB, pAkt and total Akt contents were examined by Western blot. Representative immunoblots are shown and data are presented as mean \pm SEM of three independent experiments. B-C, one-way ANOVA, followed by Bonferroni test. ${ }^{*}, p<0.05 ;{ }^{* *}, p<0.01 ;{ }^{* *}$, $\mathrm{p}<0.001$ (compared with FSH $=0$ or FSH at $0 \mathrm{~h}$ ). 
for $24 \mathrm{~h}$ and the content of $\mathrm{PHB}$ at the two follicular stages was examined. As shown in Figure 1C, FSH had no effect on PHB content in undifferentiated granulosa cells $(\mathrm{p}>0.05)$; however FSH significantly up-regulated the content of PHB $(\mathrm{p}<0.001)$ at a concentration range of $10-100 \mathrm{ng} / \mathrm{ml}$ in differentiated granulosa cells. There was no significant difference between the FSH $(200 \mathrm{ng} / \mathrm{ml})$ and the control groups. Since we have reported that Akt and PHB could regulate each other [23], we also assessed the phosphorylated and total Akt levels in this experiment. As shown in Figure $1 \mathrm{C}$, although there was a trend of decrease, FSH didn't significantly reduce Akt phosphorylation in undifferentiated granulosa cells $(p>0.05)$. In the contrast, phosphorylated Akt levels in granulosa cells in differentiated granulosa cells decreased in the presence of FSH (Figure $1 \mathrm{C}, \mathrm{p}<0.05$ ), which was reversely related to $\mathrm{PHB}$ contents.

\section{Exogenous PHB suppresses staurosporine-induced} caspase-3 cleavage and apoptosis in undifferentiated, but not differentiated, granulosa cells

Although PHB has been reported to be anti-apoptotic in undifferentiated granulosa cells $[19,20]$, whether it plays a similar role in granulosa cells after differentiation is not known. To address this question, comparison experiments were performed using undifferentiated and differentiated granulosa cells. Granulosa cells were infected with adenoviral-PHB (MOI $=40$, adenoviral-LacZ as control, 24 h) to over-express or knockdown PHB, and then cultured with the apoptosis inducer staurosporine (STS, $1 \mu \mathrm{M}, 2 \mathrm{~h}$ ). As shown in Figure 2A, whereas PHB over-expression had no effect on basal level of apoptosis in undifferentiated granulosa cells, it suppressed STS-induced caspase-3 cleavage (Figure 2A, PHB, p <0.05; STS, $\mathrm{p}<$ $0.0001 ; \mathrm{PHB} \times \mathrm{STS}, \mathrm{p}<0.05)$ and apoptosis $(\mathrm{PHB}, \mathrm{p}<0.05$; STS, $\mathrm{p}<0.0001 ; \mathrm{PHB} \times \mathrm{STS}, \mathrm{p}<0.05)$. In contrast, overexpression of $\mathrm{PHB}$ in differentiated granulosa cells had no obvious effect on STS-induced caspase-3 cleavage and apoptosis (Figure 2B), suggesting that $\mathrm{PHB}$ is antiapoptotic during preantral follicular growth but this property is lost as the cells differentiate during follicle transition into the antral stage.

\section{Knockdown of PHB increases staurosporine-induced} caspase-3 cleavage and apoptosis in undifferentiated, but not differentiated, granulosa cells

Similar experiments were performed using adenoviralshRNA to knockdown PHB in granulosa cells derived from two preparations. As shown in Figure 3, STSinduced caspase-3 cleavage and apoptosis were enhanced after knockdown of PHB in undifferentiated granulosa cells (Figure 3A, for cleaved caspase-3, shPHB, p $<0.01$;
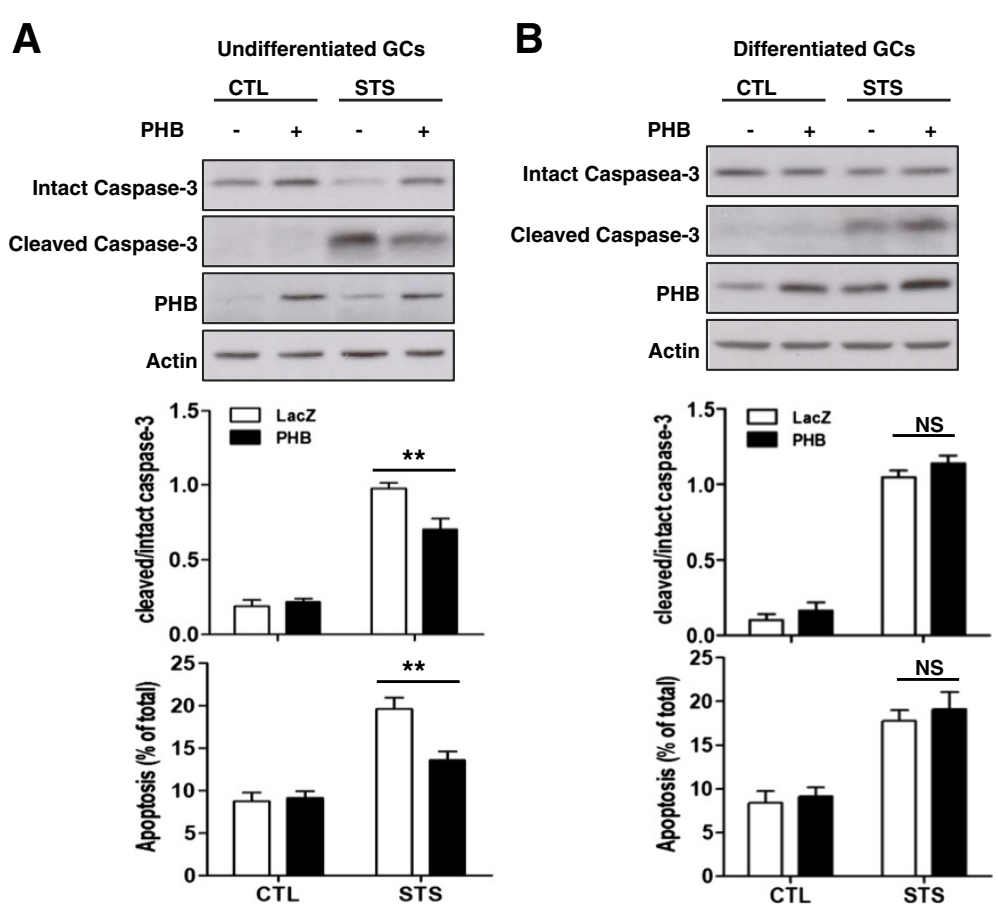

Figure 2 Effect of exogenous PHB on STS-induced caspase-3 cleavage and apoptosis. Undifferentiated (A) and differentiated (B) granulosa cells were infected with adenoviral-PHB (MOI = 40, adenoviral-lacZ as control) for $24 \mathrm{~h}$ and then cultured with STS (1 $\mu \mathrm{M}, 2 \mathrm{~h})$. The contents of cleaved, intact caspase-3 and PHB were examined by Western blot and the apoptosis rate of granulosa cells were assessed by nuclear morphology (Hoechst staining). Data are presented as mean \pm SEM of three independent experiments and analyzed by two-way ANOVA and subsequently by Bonferroni post hoc test. ${ }^{* *}, \mathrm{p}<0.01$ (compared with LacZ). NS: not significant. 
A

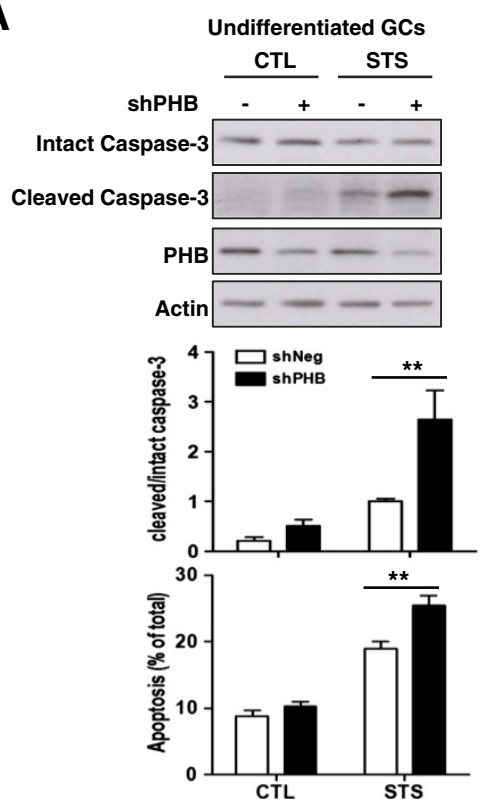

B
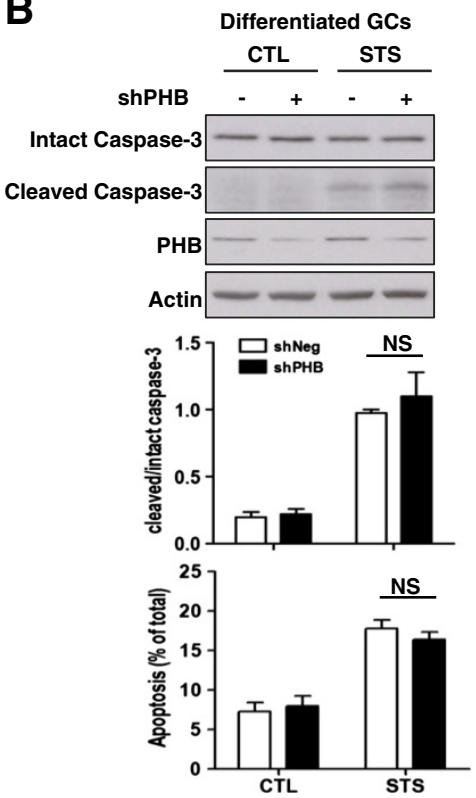

Figure 3 Effect of PHB knockdown on STS-induced caspase-3 cleavage and apoptosis. Undifferentiated (A) and differentiated (B) granulosa cells were infected with adenoviral-shPHB (MOI=10, adenoviral-shNeg as control) for $48 \mathrm{~h}$ and then cultured with STS (1 $\mu \mathrm{M}, 2 \mathrm{~h})$. The contents of cleaved, intact caspase-3 and PHB were examined by Western blot and the apoptosis rate of granulosa cells were assessed by nuclear morphology (Hoechst staining). Data are presented as mean \pm SEM of three independent experiments and analyzed by two-way ANOVA and subsequently by Bonferroni post hoc test. ${ }^{* *}, p<0.01$ (compared with LacZ). NS: not significant.

STS, $\mathrm{p}<0.0001 ; \mathrm{shPHB} \times \mathrm{STS}, \mathrm{p}<0.05$. For apoptosis, shPHB, $\mathrm{p}<0.01$; STS, $\mathrm{p}<0.0001$; $\mathrm{shPHB} \times \mathrm{STS}, \mathrm{p}<0.05)$. However, there was no effect of PHB knockdown on STSinduced caspase- 3 cleavage and apoptosis in differentiated granulosa cells (Figure 3B).

\section{Differentiated granulosa cells are more responsive to FSH in steroids production compared with undifferentiated granulosa cells}

We have previously reported that PHB suppressed FSHinduced estradiol and progesterone secretion and p450scc/ aromatase expression in undifferentiated granulosa cells [23]. As the regulatory role of PHB in granulosa cell apoptosis is dependent on the state of cellular differentiation, we then examined whether it regulate steroidogenesis differently in differentiated granulosa cells by comparing the steroidogenic responsiveness of granulosa cells at the two differentiative states. Undifferentiated and differentiated granulosa cells from two preparations were cultured with FSH $(0-100 \mathrm{ng} / \mathrm{ml}) \pm$ testosterone $(\mathrm{T}, 0.5 \mu \mathrm{M}, 24 \mathrm{~h})$, which served as a substrate of aromatase, and then the levels of estradiol and progesterone in spent medium were measured. We have previously demonstrated that $\mathrm{T}$ enhanced FSH-induced progesterone and estradiol secretion in undifferentiated granulosa cells [23]. We observed that FSHinduced progesterone production in these cells was dramatically increased in the presence of T $(5.49 \pm 0.4$ vs. 0.63 $\pm 0.13 \mathrm{ng} / \mathrm{ml}$ ) and the estradiol secretion exhibited similar effect $(48.7 \pm 5.7$ vs. $0.91 \pm 0.16 \mathrm{ng} / \mathrm{ml})$. We concomitantly tested the effect of $\mathrm{T}$ and FSH on differentiated cells (Figure 4A) and observed that $\mathrm{T}$ also enhanced FSHstimulated progesterone $(7.79 \pm 0.63$ vs. $1.22 \pm 0.98 \mathrm{ng} / \mathrm{ml})$ and estradiol secretion $(94.4 \pm 10.23$ vs. $0.88 \pm 0.14 \mathrm{ng} / \mathrm{ml})$ in differentiated granulosa cells (Figure 4A, for progesterone: FSH, $\mathrm{p}<0.001 ; \mathrm{T}, \mathrm{p}<0.001 ; \mathrm{FSH} \times \mathrm{T}, \mathrm{p}<0.001$. for estradiol: FSH, $\mathrm{p}<0.001 ; \mathrm{T}, \mathrm{p}<0.001 ; \mathrm{FSH} \times \mathrm{T}, \mathrm{p}<0.001)$. The basal levels of estradiol and progesterone at the two cellular differentiative states were similar; however production of these steroids in the presence of FSH and T was about 2-fold higher in differentiated granulosa cells than in undifferentiated granulosa cells.

\section{PHB suppresses FSH-induced steroid production in both} undifferentiated and differentiated granulosa cells

Next we examined whether PHB suppresses FSH-induced steroidogenesis in granulosa cells and if its response is dependent on the differentiated state of the cells. Granulosa cells from two preparations were infected with adenoviral-PHB (adenoviral-LacZ as control) and then cultured with FSH $(0-100 \mathrm{ng} / \mathrm{ml})$ in the presence of $\mathrm{T}$ $(0.5 \mu \mathrm{M})$ for $24 \mathrm{~h}$. The levels of estradiol and progesterone in spent medium were measured by EIA. Exogenous PHB suppressed FSH-induced steroid production and the expression of steroidogenic enzymes p450scc and aromatase in undifferentiated granulosa cells [23]. FSH-induced progesterone production in these cells was dramatically 


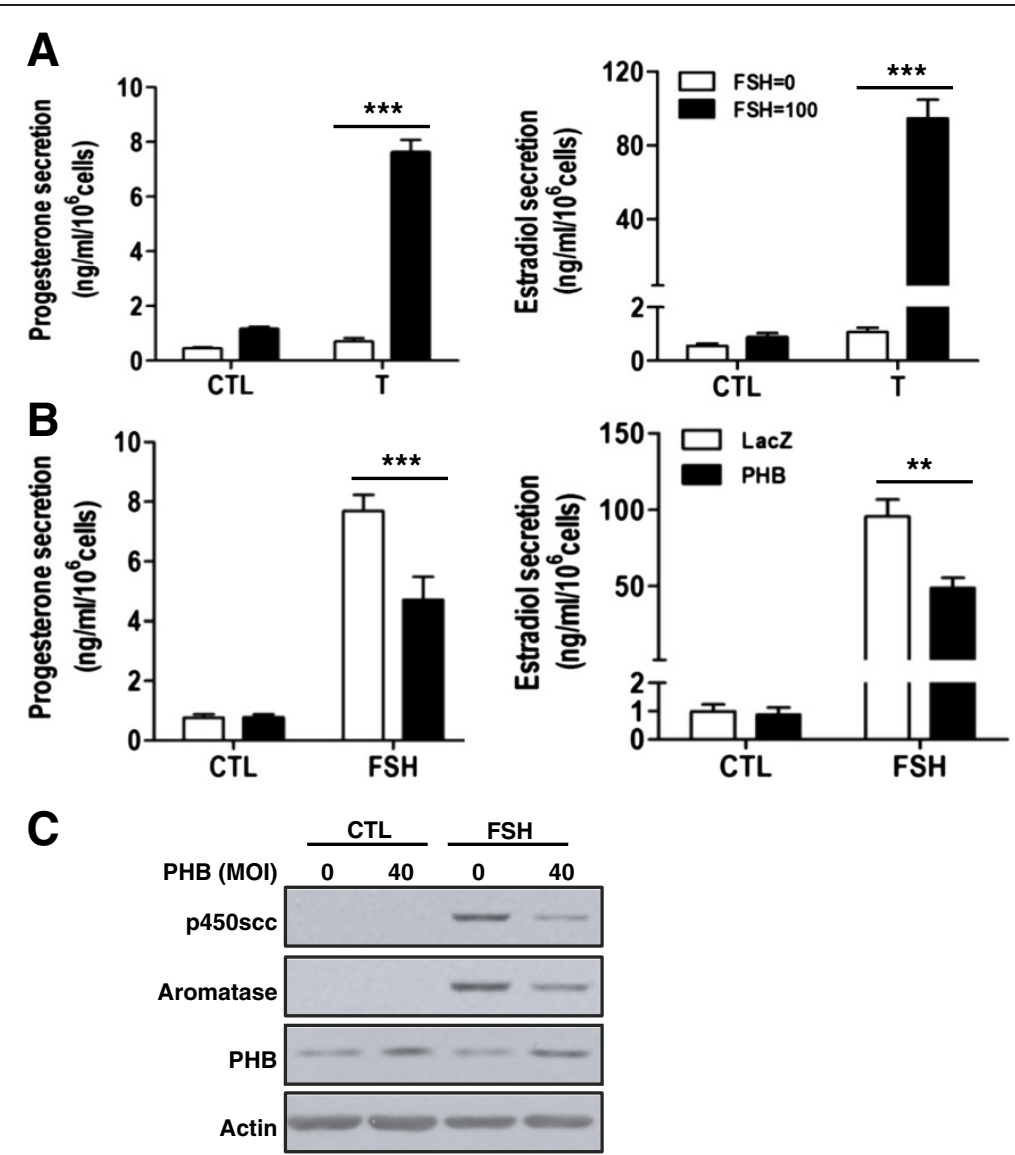

Figure 4 Influence of PHB on FSH-induced steroid production. (A) Differentiated granulosa cells were cultured with FSH $(100 \mathrm{ng} / \mathrm{ml}) \pm \mathrm{T}$ $(0.5 \mu \mathrm{M})$ for $24 \mathrm{~h}$ and the levels of progesterone and estradiol in the spent medium were measured by EIA. Data are presented as mean \pm SEM of four independent experiments and analyzed by two-way ANOVA and subsequently by Bonferroni post hoc test. ***, $\mathrm{p}<0.001$ (compared with LacZ). (B-C) Differentiated granulosa cells were infected with adenoviral-PHB ( $\mathrm{MOI}=40$, adenoviral-LacZ as control) for $24 \mathrm{~h}$ and then cultured with FSH $(100 \mathrm{ng} / \mathrm{ml}, 24 \mathrm{~h})$ in the presence of $\mathrm{T}(0.5 \mu \mathrm{M})$. Progesterone and estradiol in the spent medium (B) were measured by ElA. Data are presented as mean \pm SEM of four independent experiments and analyzed by two-way ANOVA and subsequently by Bonferroni post hoc test. **, $p<0.01 ;{ }^{* * *}$, $p<0.001$ (compared with CTL). (C) The expression of p450scc and aromatase was examined by Western blot. Representative immunoblots from three replicate experiments are shown.

suppressed by exogenous PHB (5.45 \pm 0.47 vs. $3.14 \pm 0.35$ $\mathrm{ng} / \mathrm{ml}$ ) and the estradiol secretion exhibited similar effect $(55.6 \pm 5.0$ vs. $21.76 \pm 7.72 \mathrm{ng} / \mathrm{ml})$. Concomitant studies with differentiated granulosa cells indicate that PHB similarly inhibited FSH-induced progesterone ( $7.70 \pm 0.52$ vs. $4.70 \pm 0.78 \mathrm{ng} / \mathrm{ml})$ and estradiol $(95.56 \pm 11.17$ vs. $48.96 \pm$ $6.7 \mathrm{ng} / \mathrm{ml}$ ) secretion (Figure 4B, for progesterone: $\mathrm{PHB}$, $\mathrm{p}<0.01$; FSH, $\mathrm{p}<0.001 ; \mathrm{PHB} \times \mathrm{FSH}, \mathrm{p}<0.01$. for estradiol: PHB, $\mathrm{p}<0.05 ;$ FSH, $\mathrm{p}<0.001 ; \quad \mathrm{PHB} \times \mathrm{FSH}, \quad \mathrm{p}<0.05)$ in vitro. The contents of $\mathrm{p} 450 \mathrm{scc}$ and aromatase induced by FSH were also suppressed by PHB (Figure 4C).

\section{Discussion}

In the present study, we have demonstrated the distinct roles of PHB in STS-induced apoptosis and FSHinduced steroidogenesis in granulosa cells at different stages of follicular development and thus at different cellular differentiative states. FSH regulates PHB expression in differentiated but not undifferentiated granulosa cells in vitro. PHB is anti-apoptotic and a suppressor of steroidogenesis in undifferentiated granulosa cells, while it loses its role in regulating apoptosis but maintains its latter action as the cells differentiate. These findings suggest that suppressive roles of PHB in apoptosis and steroidogenesis are precisely regulated in a follicular stage-dependent manner. The role of PHB in the regulation of apoptosis, steroidogenesis as well as proliferation $[11,12]$, the dysregulation of ovarian follicular growth and steroidogenesis in polycystic ovarian syndrome (PCOS) [26-28], together with the observations that the expression of PHB increased in a chronically androgenized rat PCOS model [23] suggest a possibility that dysregulation of PHB may be relevant to the etiology of this syndrome.

The main observation in present study is that the antiapoptotic action of PHB is evidenced at the preantral follicle stage of development, one often referred to as 
the "penultimate stage" when the destiny of the follicle (continued growth versus atresia) is determined. This observation also raise the interesting possibility that $\mathrm{PHB}$ may play an important role in deciding the fate of the granulosa cells as the follicles transition from the preantral to early antral stage. With regard to the regulation of apoptosis, PHB may execute its anti-apoptotic role by down-regulating caspase-3 cleavage and inhibiting cytochrome c release from mitochondria [20]. The loss of inhibition on apoptosis in differentiated granulosa cells may due to increased X-linked inhibitor of apoptosis protein (XIAP) expression and elevated Akt phosphorylation in these cells [29] known to inhibit apoptosis, which may modulate the action of PHB. However, we cannot rule out the possibility that PHB inhibits apoptosis via regulating the activity of transcriptional factors involved in apoptosis, as demonstrated by Fusaro et al. that PHB protects cancer cells from camptothecin-induced apoptosis via suppressing E2F1-mediated transcriptional activity [30]. While the different transcriptional factors targeted by PHB may switch off its anti-apoptotic function, this hypothesis needs further investigation.

In contrast, the participation of PHB in the control of steroidogenesis in both undifferentiated and differentiated granulosa cells is consistent with important intraovarian regulatory role of steroids during follicular development and the involvement of PHB in the control of the steroidogenic processes. The mechanism by which PHB acts as a steroidogenesis-suppressor or anti-apoptotic factor during follicular development and the physiological signal that drives these responses are unknown. PHB is shown to be regulated by the novel adipokine chemerin in vitro and it mediates the suppressive role of chemerin on FSHinduced steroidogenic enzyme expression in undifferentiated granulosa cells [23]. Because PHB is a co-activator or co-repressor of distinct transcriptional factors (p53, E2F, $E R \alpha)[7,17,18]$ and we have observed an interaction of PHB and NR5a1/2 in freshly isolated rat granulosa cells (Additional file 1: Figure S1), it is possible that PHB suppresses steroidogenesis via acting as a co-repressor of transcriptional factors targeting steroidogenic enzymes, such as nuclear receptors NR5a1/NR5a2, C/EBP [31-34]. Further studies on promoter activity, DNA mutagenesis and protein-protein interaction assay are needed to test this possibility. However, we cannot rule out the possibility that PHB may regulate the mRNA expression of FSH receptor.

Besides PHB, other proteins have also been reported to be differentially regulated and play various functions in ovarian cells from different follicular stages. Plasminogen activator plays a crucial role in the dynamic tissue remodeling during follicular development and ovulation [35,36]. Its activity is increased by FSH, and inhibited by transforming growth factor $\alpha$, in undifferentiated granulosa cells but decreased in differentiated ones [37,38]. Another example is C-type natriuretic peptide (CNP), which binds to its receptor and promotes preantral follicle growth via stimulating the cGMP release in undifferentiated granulosa cells; however CNP is unable to increase cGMP level in differentiated granulosa cells [39]. The cell differentiationdependent regulation of intra-ovarian and intracellular factors may facilitate the precise control of granulosa cell fate and function during follicular development.

Although the functions of PHB are reported to regulate many cellular processes in various cell types, how its expression is regulated is largely unknown. The regulation of PHB by gonadotropin in the literature is controversial. We demonstrated that gonadotropin in vivo reduced $\mathrm{PHB}$ mRNA abundance; however others reported that PHB mRNA levels and protein contents are not altered [40] or higher after gonadotropin treatment [21]. While the reasons for these apparent differences are not immediately clear, whether differences in the dosages of gonadotropin used and/or in the methods of granulosa cell isolation could account for the different outcome, remains to be determined. In this context, our results also indicated that high concentration of FSH $(200 \mathrm{ng} / \mathrm{ml})$ failed to increase PHB expression in vitro whereas lower concentration did (Figure 1C). The effect of high doses of FSH or other molecules on gene expression has been well documented and an effective negative feedback mechanism to precisely control gene expression may be operational. FSH receptor is desensitized and down-regulated by long exposure of high dose of FSH [41-43], accompanied by reduced cyp19 expression and estradiol production in granulosa cells [43]. In addition, anti-Müllerian hormone, known to inhibit FSH-induced aromatase expression, is also upregulated by low but down-regulated by high dose of FSH [43]. Low dose of AMH stimulates inhibin B level in human granulosa cells while the opposite was true with higher dosages [44].

The mechanism by which FSH regulates PHB expression is unclear. It is known that FSH acts through multiple signaling pathways, including cAMP/PKA, PI3K/Akt and MAPK, and via various transcriptional factors, such as forkhead box O1, cAMP regulatory element binding protein and specific protein 1 (Sp1) [45-48]. In addition to putative binding sites for CCAAT/enhancer-binding protein $(\mathrm{C} / \mathrm{EBP})$ and insulin response element in the promoter of PHB [49], there are other DNA binding elements such as E2F, GATA, ER and Sp1 as predicted by the transcription element search system. It is possible that the transcription factors maintaining PHB expression in undifferentiated granulosa cells is switched to others in differentiated granulosa cells due to the distinct cellular contents. However, the particular transcription factor involved in the regulation of PHB in granulosa cells at the two stages of cellular differentiation needs to be further investigated. 
It is well known that FSH stimulates Akt phosphorylation in ovarian cells [45]. Our present studies extent these findings and show that the rapid increase of phosphorylated Akt content in response to FSH is dependent on the state of cellular differentiation. Since the phosphorylated Akt content is a consequence of both kinase and phosphatase activities [50], it was of interest to determine whether this signal is removed with a different efficiency between different state of differentiation and whether the decreased pAkt levels are correlated with increased PHB contents. Our results indicated that the efficiency at which the PI3K-Akt signaling pathway is turned on and off by FSH is also dependent on the state of cellular differentiation and may be related to the action of PHB. The reverse correlation of PHB and pAkt content was supported by a recent finding that PHB and Akt could regulate the expression of each other [23].

In our culture system, both undifferentiated and differentiated granulosa cells exhibited a robust steroidogenic response to FSH. Basal and FSH-induced estradiol secretion in undifferentiated granulosa cells were lower than those in differentiated granulosa cells in the presence of testosterone, which could be due to higher basal levels of p450scc and aromatase induced by gonadotropin with increased granulosa cell differentiation (this study, [51]). Testosterone was added in the culture as the substrate of aromatase, which is commonly used in the studies on FSH-induced estrogen production [45,52,53]. It is also possible that testosterone not only acted as a substrate in granulosa cells, but also augmented the action of FSH on the production of progesterone and estradiol $[52,54,55]$.

\section{Conclusion}

Our findings demonstrate that PHB expression is regulated by FSH in a follicular stage-dependent manner in vitro and the roles of PHB as an anti-apoptotic factor and in the regulation of steroidogenesis are dependent on the differentiation status of granulosa cells. It is an inhibitor of steroidogenesis in both undifferentiated and differentiated granulosa cells, but is anti-apoptotic in undifferentiated granulosa cells. This study significantly improves our understanding of the role of PHB in the ovary although the mechanism by which PHB suppresses apoptosis and steroidogenesis and the factors involved in the regulation of PHB remains to be investigated.

\section{Additional file}

Additional file 1: Figure S1. Interaction of PHB and NR5a1/2.

Granulosa cells were collected from eCG-primed rats and then lyzed in IP lysis buffer. Endogenous PHB in $500 \mu \mathrm{g}$ cell lysate was

immunoprecipitated with $2 \mu \mathrm{g}$ mouse anti-PHB antibody (normal mouse IgG as control), subjected to 15\% SDS-PAGE and probed with the antibodies targeting PHB, NR5a1 and NR5a2, respectively. Darker bands in Western blot indicate the heavy or light chain of lgG.

\section{Abbreviations}

PHB: Prohibitin; STS: Staurosporine; eCG: Equine chronic gonadotropin; DES: Diethylstilbestrol; ECL: Enhanced chemiluminescent; MOI: Multiplicity of infection; ElA: Enzyme immunoassay; T: Testosterone; p450scc: P450 side-chain cleavage enzyme.

\section{Competing interests}

The authors declare that they have no competing interests.

\section{Authors' contributions}

QW performed the experiments, prepared the data and drafted the manuscript. AL and BKT are co-mentors, provided input of studies and edited the manuscript. All authors read and approved the final manuscript.

\section{Acknowledgement}

This study is supported by Canadian Institutes of Health Research (CIHR; MOP-119381), the World Class University (WCU) program through the Ministry of Education, Science and Technology and funded by the National Research Foundation of Korea (R31-10056), Human Reproduction Research Fund of the Ottawa Fertility Centre, and CIHR-QTNPR Graduate Scholarship and CIHR-REDIH Graduate Scholarship (QW).

\section{Author details}

Department of Cellular \& Molecular Medicine, University of Ottawa, Ottawa, Ontario, K1H 8L6, Canada. ${ }^{2}$ Chronic Disease Program, Ottawa Hospital Research Institute, The Ottawa Hospital-General Campus, Mail Box \#511501 Smyth Road, Ottawa, Ontario K1H 8L6, Canada. ${ }^{3}$ Reproductive Biology Unit, Department of Obstetrics and Gynaecology, University of Ottawa, Ottawa, Ontario K1H 8L6, Canada. ${ }^{4}$ Ottawa Fertility Centre, Ottawa, Ontario K2C 3V4, Canada. ${ }^{5}$ WCU Biomodulation Major, Department of Agricultural Biotechnology, College of Agriculture and Life Sciences, Seoul National University, Seoul, Republic of Korea.

Received: 28 January 2013 Accepted: 27 March 2013

Published: 8 April 2013

\section{References}

1. McGee EA, Hsueh AJ: Initial and cyclic recruitment of ovarian follicles. Endocr Rev 2000, 21:200-214.

2. Craig J, Orisaka M, Wang H, Orisaka S, Thompson W, Zhu C, Kotsuji F, Tsang BK: Gonadotropin and intra-ovarian signals regulating follicle development and atresia: the delicate balance between life and death. Front Biosci 2007, 12:3628-3639.

3. Woods DC, Haugen MJ, Johnson AL: Actions of epidermal growth factor receptor/mitogen-activated protein kinase and protein kinase $C$ signaling in granulosa cells from Gallus gallus are dependent upon stage of differentiation. Biol Reprod 2007, 77:61-70.

4. Richards JS: Hormonal control of gene expression in the ovary. Endocr Rev 1994, 15:725-751.

5. Mishra $S$, Ande SR, Nyomba BL: The role of prohibitin in cell signaling. FEBS J 2010, 277:3937-3946.

6. Mishra S, Murphy LC, Nyomba BL, Murphy LJ: Prohibitin: a potential target for new therapeutics. Trends Mol Med 2005, 11:192-197.

7. Fusaro G, Dasgupta P, Rastogi S, Joshi B, Chellappan S: Prohibitin induces the transcriptional activity of p53 and is exported from the nucleus upon apoptotic signaling. J Biol Chem 2003, 278:47853-47861.

8. Brasaemle DL, Dolios G, Shapiro L, Wang R: Proteomic analysis of proteins associated with lipid droplets of basal and lipolytically stimulated 3T3-L1 adipocytes. J Biol Chem 2004, 279:46835-46842.

9. Mengwasser J, Piau A, Schlag P, Sleeman JP: Differential immunization identifies PHB1/PHB2 as blood-borne tumor antigens. Oncogene 2004, 23:7430-7435

10. Kang X, Zhang L, Sun J, Ni Z, Ma Y, Chen X, Sheng X, Chen T: Prohibitin a potential biomarker for tissue-based detection of gastric cancer. J Gastroenterol 2008, 43:618-625.

11. Nuell MJ, Stewart DA, Walker L, Friedman V, Wood CM, Owens GA, Smith JR, Schneider EL, Dell' Orco R, Lumpkin CK, et al: Prohibitin, an evolutionarily conserved intracellular protein that blocks DNA synthesis in normal fibroblasts and HeLa cells. Mol Cell Biol 1991, 11:1372-1381. 
12. Roskams AJ, Friedman V, Wood CM, Walker L, Owens GA, Stewart DA, Altus MS, Danner DB, Liu XT, McClung JK: Cell cycle activity and expression of prohibitin mRNA. J Cell Physio/ 1993, 157:289-295.

13. McClung JK, Jupe ER, Liu XT, Dell'Orco RT: Prohibitin: potential role in senescence, development, and tumor suppression. Exp Gerontol 1995, 30:99-124.

14. Rastogi S, Joshi B, Dasgupta P, Morris M, Wright K, Chellappan S: Prohibitin facilitates cellular senescence by recruiting specific corepressors to inhibit E2F target genes. Mol Cell Biol 2006, 26:4161-4171.

15. Kasashima K, Ohta E, Kagawa $Y$, Endo H: Mitochondrial functions and estrogen receptor-dependent nuclear translocation of pleiotropic human prohibitin 2. J Biol Chem 2006, 281:36401-36410.

16. Nijtmans LG, de Jong L, Artal Sanz M, Coates PJ, Berden JA, Back JW, Muijsers AO, van der Spek $H$, Grivell LA: Prohibitins act as a membranebound chaperone for the stabilization of mitochondrial proteins. EMBO J 2000, 19:2444-2451.

17. Choi D, Lee SJ, Hong S, Kim H, Kang S: Prohibitin interacts with RNF2 and regulates E2F1 function via dual pathways. Oncogene 2008, 27:1716-1725.

18. He B, Feng Q, Mukherjee A, Lonard DM, DeMayo FJ, Katzenellenbogen BS, Lydon JP, O'Malley BW: A repressive role for prohibitin in estrogen signaling. Mol Endocrinol 2008, 22:344-360.

19. Chowdhury I, Branch A, Olatinwo M, Thomas K, Matthews R, Thompson WE: Prohibitin (PHB) acts as a potent survival factor against ceramide induced apoptosis in rat granulosa cells. Life Sci 2011, 89:295-303.

20. Chowdhury I, Xu W, Stiles JK, Zeleznik A, Yao X, Matthews R, Thomas K, Thompson WE: Apoptosis of rat granulosa cells after staurosporine and serum withdrawal is suppressed by adenovirus-directed overexpression of prohibitin. Endocrinology 2007, 148:206-217.

21. Thompson WE, Asselin E, Branch A, Stiles JK, Sutovsky P, Lai L, Im GS Prather RS, Isom SC, Rucker E 3rd, Tsang BK: Regulation of prohibitin expression during follicular development and atresia in the mammalian ovary. Biol Reprod 2004, 71:282-290.

22. Chowdhury I, Garcia-Barrio M, Harp D, Thomas K, Matthews R, Thompson WE: The emerging roles of prohibitins in folliculogenesis. Front Biosci (Elite Ed) 2012, 4:690-699.

23. Wang Q, Leader A, Tsang BK: Inhibitory roles of prohibitin and chemerin on FSH-induced rat granulosa cell steroidogenesis. Endocrinology 2013 154:956-967.

24. Campbell KL: Ovarian granulosa cells isolated with EGTA and hypertonic sucrose: cellular integrity and function. Biol Reprod 1979, 21:773-786.

25. Wang $H$, Jiang JY, Zhu C, Peng C, Tsang BK: Role and regulation of nodal/ activin receptor-like kinase 7 signaling pathway in the control of ovarian follicular atresia. Mol Endocrinol 2006, 20:2469-2482

26. Jakimiuk AJ, Weitsman SR, Navab A, Magoffin DA: Luteinizing hormone receptor, steroidogenesis acute regulatory protein, and steroidogenic enzyme messenger ribonucleic acids are overexpressed in thecal and granulosa cells from polycystic ovaries. J Clin Endocrinol Metab 2001, 86:1318-1323.

27. Jonard S, Dewailly D: The follicular excess in polycystic ovaries, due to intra-ovarian hyperandrogenism, may be the main culprit for the follicular arrest. Hum Reprod Update 2004, 10:107-117.

28. Wang Q, Kim JY, Xue K, Liu JY, Leader A, Tsang BK: Chemerin, a novel regulator of follicular steroidogenesis and its potential involvement in polycystic ovarian syndrome. Endocrinology 2012, 153:5600-5611.

29. Asselin E, Wang Y, Tsang BK: X-linked inhibitor of apoptosis protein activates the phosphatidylinositol 3-kinase/Akt pathway in rat granulosa cells during follicular development. Endocrinology 2001, 142:2451-2457.

30. Fusaro G, Wang S, Chellappan S: Differential regulation of Rb family proteins and prohibitin during camptothecin-induced apoptosis. Oncogene 2002, 21:4539-4548.

31. Boerboom D, Pilon N, Behdjani R, Silversides DW, Sirois J: Expression and regulation of transcripts encoding two members of the NR5A nuclear receptor subfamily of orphan nuclear receptors, steroidogenic factor-1 and NR5A2, in equine ovarian cells during the ovulatory process. Endocrinology 2000, 141:4647-4656.

32. Hinshelwood MM, Repa JJ, Shelton JM, Richardson JA, Mangelsdorf DJ, Mendelson CR: Expression of LRH-1 and SF-1 in the mouse ovary: localization in different cell types correlates with differing function. Mol Cell Endocrinol 2003, 207:39-45.

33. Reinhart AJ, Williams SC, Stocco DM: Transcriptional regulation of the StAR gene. Mol Cell Endocrinol 1999, 151:161-169.
34. Andrieu T, Pezzi V, Sirianni R, Le Bas R, Feral C, Benhaim A, Mittre H: cAMPdependent regulation of CYP19 gene in rabbit preovulatory granulosa cells and corpus luteum. J Steroid Biochem Mol Biol 2009, 116:110-117.

35. Ny T, Wahlberg P, Brandstrom IJ: Matrix remodeling in the ovary: regulation and functional role of the plasminogen activator and matrix metalloproteinase systems. Mol Cell Endocrinol 2002, 187:29-38.

36. Reich R, Miskin R, Tsafriri A: Intrafollicular distribution of plasminogen activators and their hormonal regulation in vitro. Endocrinology 1986, 119:1588-1593.

37. Karakji EG, Tsang BK: Follicular stage-dependent regulation of rat granulosa cell plasminogen activator system by transforming growth factor-alpha in vitro. Biol Reprod 1995, 52:411-418.

38. Karakji EG, Tsang BK: Tumor necrosis factor alpha inhibits rat granulosa cell plasminogen activator activity in vitro during follicular development. Biol Reprod 1995, 52:745-752

39. Noubani A, Farookhi R, Gutkowska J: B-type natriuretic peptide receptor expression and activity are hormonally regulated in rat ovarian cells. Endocrinology 2000, 141:551-559.

40. Thompson WE, Powell JM, Whittaker JA, Sridaran R, Thomas KH: Immunolocalization and expression of prohibitin, a mitochondrial associated protein within the rat ovaries. Anat Rec 1999, 256:40-48.

41. Simoni M, Gromoll J, Nieschlag E: The follicle-stimulating hormone receptor: biochemistry, molecular biology, physiology, and pathophysiology. Endocr Rev 1997, 18:739-773.

42. Minegishi T, Tano M, Kishi H, Kameda T, Miyamoto K: Follicle-stimulating hormone regulation on its receptor messenger ribonucleic acid levels in cultured rat granulosa cells. Biochim Biophys Acta 1997, 1359:165-173.

43. Scheetz D, Folger JK, Smith GW, Ireland JJ: Granulosa cells are refractory to FSH action in individuals with a low antral follicle count. Reprod Fertil Dev 2012, 24:327-336.

44. Pellatt L, Rice S, Dilaver N, Heshri A, Galea R, Brincat M, Brown K, Simpson ER, Mason HD: Anti-Mullerian hormone reduces follicle sensitivity to follicle-stimulating hormone in human granulosa cells. Fertil Steril 2011, 96:1246-1251. e1241

45. Wayne CM, Fan HY, Cheng X, Richards JS: Follicle-stimulating hormone induces multiple signaling cascades: evidence that activation of Rous sarcoma oncogene, RAS, and the epidermal growth factor receptor are critical for granulosa cell differentiation. Mol Endocrinol 2007, 21:1940-1957.

46. Fang WL, Lee MT, Wu LS, Chen YJ, Mason J, Ke FC, Hwang JJ: CREB coactivator CRTC2/TORC2 and its regulator calcineurin crucially mediate follicle-stimulating hormone and transforming growth factor beta1 upregulation of steroidogenesis. J Cell Physiol 2012, 227:2430-2440.

47. Mayr B, Montminy M: Transcriptional regulation by the phosphorylationdependent factor CREB. Nat Rev Mol Cell Biol 2001, 2:599-609.

48. Saxena D, Escamilla-Hernandez R, Little-Ihrig L, Zeleznik AJ: Liver receptor homolog-1 and steroidogenic factor-1 have similar actions on rat granulosa cell steroidogenesis. Endocrinology 2007, 148:726-734.

49. Ande SR, Xu Z, Gu Y, Mishra S: Prohibitin has an important role in adipocyte differentiation. Int J Obes (Lond) 2012, 36:1236-1244.

50. Bayascas JR, Alessi DR: Regulation of Akt/PKB Ser473 phosphorylation. Mol Cell 2005, 18:143-145.

51. Liu WK, Bousfield GR, Moore WT Jr, Ward DN: Priming procedure and hormone preparations influence rat granulosa cell response. Endocrinology 1985, 116:1454-1459.

52. Zeleznik AJ, Saxena D, Little-lhrig L: Protein kinase B is obligatory for follicle-stimulating hormone-induced granulosa cell differentiation. Endocrinology 2003, 144:3985-3994.

53. Escamilla-Hernandez R, Little-lhrig L, Zeleznik AJ: Inhibition of rat granulosa cell differentiation by overexpression of Galphaq. Endocrine 2008, 33:21-31.

54. Armstrong DT, Dorrington JH: Androgens augment FSH-induced progesterone secretion by cultured rat granulosa cells. Endocrinology 1976, 99:1411-1414.

55. Harlow CR, Shaw HJ, Hillier SG, Hodges JK: Factors influencing folliclestimulating hormone-responsive steroidogenesis in marmoset granulosa cells: effects of androgens and the stage of follicular maturity. Endocrinology 1988, 122:2780-2787.

doi:10.1186/1757-2215-6-23

Cite this article as: Wang et al:: Follicular stage-dependent regulation of apoptosis and steroidogenesis by prohibitin in rat granulosa cells. Journal of Ovarian Research 2013 6:23. 